\title{
A NEW BIOLOGICAL BRADYKININ-LIKE PEPTIDE IN RAT STOMACH
}

\author{
Motoki KOBAYASHI and Katsuya OHATA \\ Department of Pharmacology, Kyoto College of Pharmacy, \\ Yamashina, Kyoto 607, Japan
}

Accepted February 8, 1981

The existence of a bradykinin (BK)-like peptide ( $P 1)$, the retention time of which was distinct from that of BK, kallidin and methionyl-lysyl-BK (MLBK) on the chromatography on SP-Sephadex C-25, was reported in a previous paper (1). In the present report, further purification of P1 was carried out by paper electrophoresis (PE). The homogeneity of the preparation, which has $\mathrm{P} 1$ activity, was determined by thin-layer chromatography (TLC). The qualitative amino acid analysis of P1 was carried out with the two-dimensional TLC.

PE was performed on Toyo 51A filter paper (Toyo Roshi Kaisha, LTD., Japan) using a Model SJ-1060A multipurpose electrophoresis apparatus (Atto Scientific Industry Co., LTD., Japan). The densitometry was carried out with a Model CS-910 dual wavelength TLC scanner (Shimadzu Scientific Instruments, INC., Japan). The electrophoretic mobility of the material was calculated relatively to arginine as the standard marker. TLC was carried out with HPTLC plates silica gel 60 precoated (E. Merck AG, Germany). The qualitative amino acid analysis and $\mathrm{NH}_{2}$-terminal determination of the preparation were carried out by the labeling with dansyl chloride (DNS-Cl, 5-dimethylamino-1-naphtalenesulfonyl chloride. E. Merck AG, Germany) described below and by the method of Woods and Wang (2) with two-dimensional TLC on polyamide layer (TLC Ready-Plastic Sheets, F-1700. Micro-Polyamide, Schleicher and
Shull, Germany). The chromatogram of DNS-derivatives on the polyamide layer was recorded by photograph of the fluorescence by ultraviolet light with a Polaroid camera. The labeling with DNS-Cl was carried out by the method of Bruton and Hartley (3). The assay with the isolated rat uterus was carried out by the method as described previously (1).

The preparation containing $\mathrm{P} 1$, obtained by the method in the previous paper (1), was submitted to PE. Fig. 1 shows the pattern of ninhydrin, or chlorine and o-tolidine stainable spots of the preparation and arginine, obtained after PE. The densitometer curve of the ninhydrin staining spots of the preparation, obtained by reflection linear scanning at $570 \mathrm{~nm}$, was shown in Fig. 1-a. The preparation gave two spots (S1 and S2 whose mobilily relative to arginine were 0.09 and 0.47 . respectively) after $\mathrm{PE}$ at $\mathrm{pH} 6.5$ (Fig. 1-a), whereas one spot whose mobility relative to arginine was 0.62 after $P E$ at pH 3.5 (Fig. 1-b).

In Fig. 1-a, the strips (5 $\mathrm{mm}$ in width) of the region 1 to 6 obtained from the unstained paper corresponding to the stained spot on the guide strip were extracted with methanol, and the extracts were lyophilized. Each part of the dried residues (P1-1 to P1-6, respectively) obtained from the region 1 to 6 were dissolved in $0.9 \%$ saline and the resultant solutions were tested using isolated rat uterus. The dried residues ( $P 1-3$ to $P 1-5$ ) which had the uterine-contractile activity 


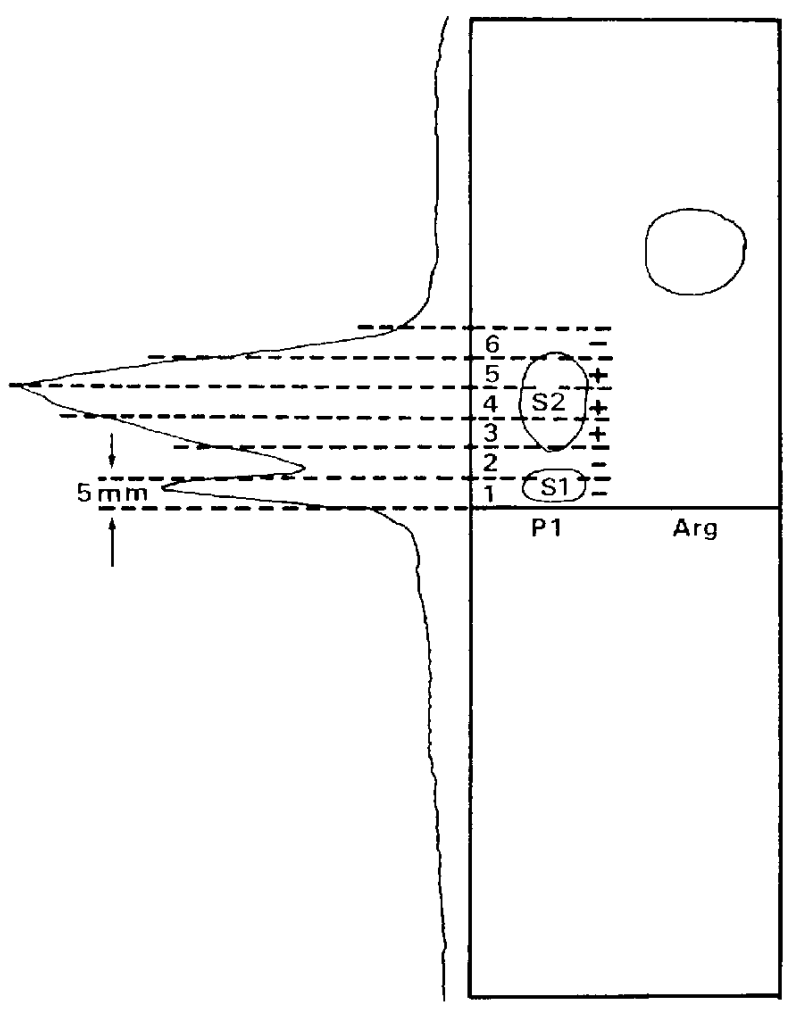

(a)

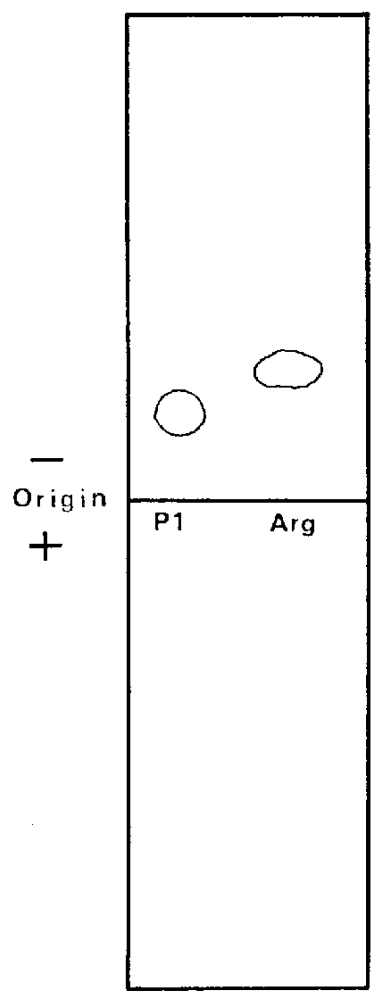

(b)

Fig. 1. Paper electrophoresis (PE) of the preparation containing P1. (a) drawing of the patterns of stainable materials on the guide strip and the densitometer curve of the staining spots at $570 \mathrm{~nm}$ obtained after PE with the buffer (pyridine/acetic acid/water $40: 1.2: 360, \mathrm{pH}$ 6.5), and distribution of the rat uterine-contractile activity detected from the preparative strip. The signs of plus and minus indicate the presence and the absence of the rat uterine-contractile activity, respectively. Conditions: $80 \mathrm{~min}$ at 25 volts per $\mathrm{cm}$, ninhydrin stain. (b) drawing of the patterns of stainable material obtained after PE with the buffer (pyridine/acetic acid/water 2:20:380, pH 3.5). Conditions: $70 \mathrm{~min}$ at 30 volts per $\mathrm{cm}$, chlorine and o-tolidine stain. Arg indicates arginine as the standard marker.

were combined, and submitted to TLC for the determination of homogeneity, and qualitative amino acid analysis.

The DNS-derivative of the preparation containing P1-3 to P1-5, obtained from PE. was chromatographed on silica gel plate and gave one fluorescent spot having $\mathrm{Rf}$ value $=0.72$ which was different from that of $B K$ and neurotensin (0.58 and 0.69 , respectively) using the solvent ( $n$-butanol/pyridine/acetic acid/water 15:10:3:12).

For the qualitative amino acid analysis and
$\mathrm{NH}_{2}$-terminal determination, the preparation containing $\mathrm{P} 1-3$ to $\mathrm{P} 1-5$, obtained from PE. was also hydrolyzed with $5.7 \mathrm{~N} \mathrm{HCl}$ at $105^{\circ} \mathrm{C}$ for $10-12 \mathrm{hr}$ before or after the labeling with DNS-Cl, respectively. As shown in Fig. 2, P1 was the peptide containing thirteen amino acids: arginine. proline, glycine, phenylalanine, serine, valine. leucine, isoleucine, alanine, lysine, threonine. glutamic acid and aspartic acid. Whether or not tryptophan is contained in the molecule of $P 1$ is unknown as this compound may be 
destroyed through hydrolysis. The $\mathrm{NH}_{2}-$ terminal determination gave only $\varepsilon$-DNSIysine and no $\alpha$-DNS-amino acid. The $\alpha$-amino group of the $\mathrm{NH}_{2}$-terminal residue of P1 seems to be blocked, or may be tryptophan. The result on TLC with silica gel plate
A

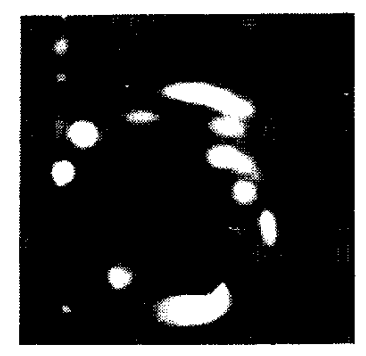

B
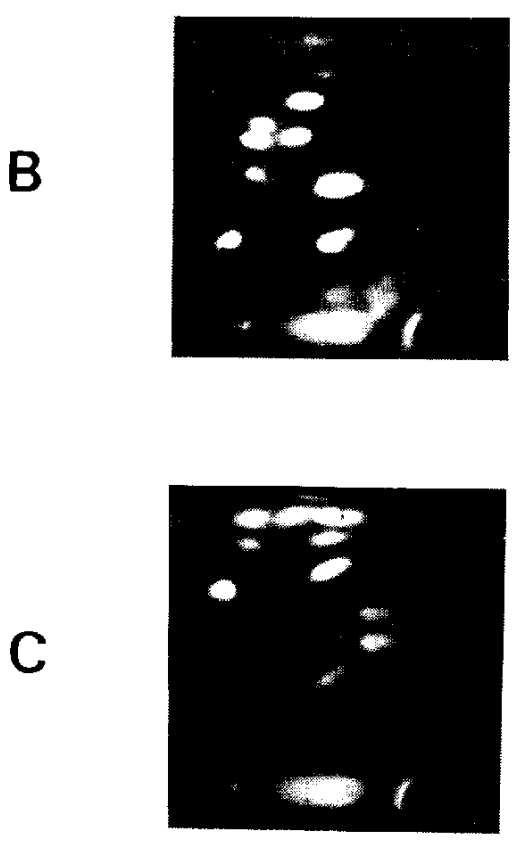
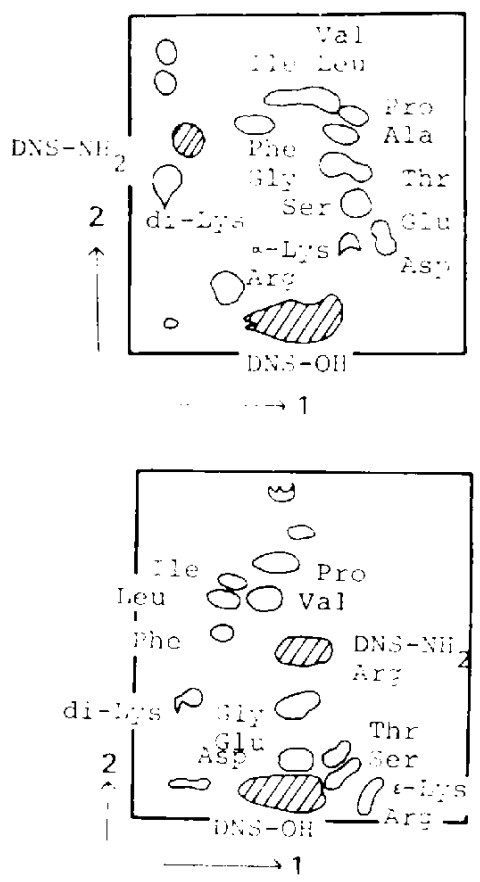

Ile pro

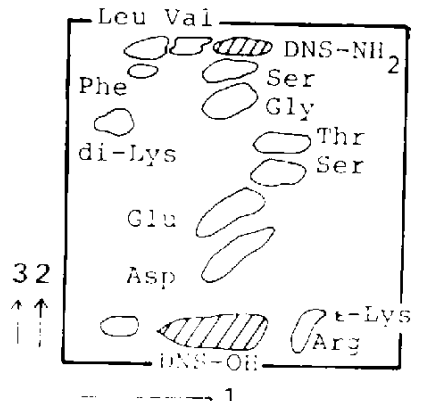

Fig. 2. Two-dimensianal thin-layer ctromatography of dansyl (DVS)-derivatives of the hydrolyzed preparation of purifico P1, obtained from paper electrophoresis. The directions of dovelopment are indicated by the arrows. By-products are indicated by the hatched areas. A map of the chromitogram is shown to complement tho identification of the individual DNS-compounds. A: The first direction. 28\% ammonia/water 1:100. The second direction. formic acid/n-butanol/heptane $1: 10: 10$. The existence of the spots of DNS-derivatives of arginine, proline, glycine, phenylalanine, serine, alanine, lysine and threonine was confimed. B: The first dircction. formic acid/water 3:200. The second direction, benzene/acetic acid 9:1. The existence of the spots of DNS-derivatives of valine, loucine and isoleucine was confirmed. C: B was rechromatographed with the third solvent system (ethyl acetate/methanolacetic acid 20:1:1) to the direction of the second dimersion. The existence of the spots of DNS-derivatives of glutamic acid and aspartic acid was confirmed. 
shows that the preparation which has P1 activity, obtained from PE, is homogeneous.

Several lines of evidence show that $P 1$ is a new biological BK-like peptide of mammalian origin. In the present study, the DNS-derivative of $P 1$ had an Rf value which differed from that of BK and neurotensin. The absence of tyrosine in the molecule of P1 also distinguished P1 from neurotensin. We have shown that $P 1$ is distinct from $B K$. kallidin and MLBK by the difference of the retention time on the chromatography on SP-Sephadex C-25 (1). The kinins released by pepsin from various kininogens, which have been reported by Habermann (4, 5), Hochstrasser and Werle (6) and Guimaraes et al. (7), have MLBK in the crucial part of the amino acid sequence. $P 1$ does not contain MLBK in the sequence, because P1 does not contain methionine in the molecule. Guimaraes et al. (7) demonstrated that the maximal kinin release by pepsin occurs around $\mathrm{pH}$ 1.0. Chang et al. (8) found that the catheptic enzyme (leukokininogenases) of polymorphonuclear leukocyte cells and macrophages releases leukokinins at pH 4.0. We have found that the kinin-forming enzyme (KFE), the optimum $\mathrm{pH}$ of which is observed at 4.8 , exists in the rat stomach (9), and that the KFE is similar to cathepsin D (in preparation). The presence of isoleucine and the absence of tyrosine and histidine in the molecule of P1 distinguish P1 from the leukokinins. $\mathrm{P} 1$ and the leukokinins are alike in that they do not contain methionine and cysteine. Whether or not P1 is released by the KFE from the plasma kininogen and has a sequence similiar to that of the leukokin ins is the subject of ongoing investigations.

\section{REFERENCES}

1) Kobayashi, M., Shikimi, T., Miyata, S. and Ohata, K.: A bradykinin-like substance in rat stomach. Japan. J. Pharmacol. 30, 701-710 (1980)

2) Woods, K.R. and Wang, K.T.: Separation of dansyl-amino acids by polyamide layer chromatography. Biochem. Biophys. Acta 133, $369-370(196 \%)$

3) Bruton, C.J. and Hartley, B.S.: Chemical stuoies on methionyl-tRNA synthetase from Escherichia coli. J. molec. Biol. 52, 165-178 (1970)

4) Habermann, E.: Isolierung. Pnarmakologische Eigerschafton. Struk:urautklärung und Spalturg peptischer kininliefernder Fragmente (PKF) aus Rinderserum-Kininogen. Vaunyn-Schmiedeberg's Arch exp. Pati. Pharmakol. 251, $187-$ 188 (1965)

5) Habermann, E.: Strukturaufklärung kininliefornder Peptide aus Rinderserum Kininogen. Naunyn-Schmicdeberg's Arch. exp. Path. Pharmakul. 253, 474-483 (1966)

6) Hochstrasser, K. and Werle, E.: Über kininliefernde Poptide aus pepsinverdauten Rinderplasmaproteinen. Hoppe-Seyler's Z. Physiol. Chem. 348, 177-182 (1967)

7) Guimaraes, J.A., Pierce. J.V., Hial, B. and Pisano, J.J.: Methionyl-lysyl-bradykinin: The kinin releascd by pepsin from numan kininogens. Adv. exp. Med. Bicl. 70, 265-269 (1976)

8) Chang, J., Freer, R., Stella, R. and Greenbaum, L.H.: Studios on leukokinins-11, Studies on the formation, partial amino acid sequence and chemical properties of leukokinins $M$ and PM $V$. Biochem. Pharmacol. 21, 3095-3106 (1972)

9) Kobayashi, M., Shikimi, T., Miyata, S. and Ohata, K.: Studies on kinin-forming enzyme in rat stomach. Japan. J. Pharmacol. 29, 947-950 (1979) 